See discussions, stats, and author profiles for this publication at: https://www.researchgate.net/publication/271846184

\title{
La presencia festiva del Quijote en los virreinatos americanos
}

Chapter · January 2007

\section{CITATIONS}

1 author:

A.

Judith Farre

Spanish National Research Council

32 PUBLICATIONS 20 CITATIONS

SEE PROFILE
READS

15

Some of the authors of this publication are also working on these related projects:

From the Edges of the Archive, II: Ephemeral Writing in the Viceroyalties of the Indies (ELBA) View project 


\section{LA PRESENCIA FESTIVA DE EL QUIJOTE EN LOS VIRREINATOS AMERICANOS}

Judith Farré Vidal

(Tecnológico de Monterrey)

Las disposiciones legales de 1531 y 1534 prohibieron imprimir en América ${ }^{1}$ «libros de romance de historias vanas o de profanidad», aunque ello no impidió la difusión de El Quijote y otras obras de Cervantes, que figuran en las listas de envío de libros hacia América. $\mathrm{El}$ auge de prohibiciones que pretendía regular el trasvase de este tipo de libros de ficción «como son de Amadís e otros de esta calidad, porque este es mal ejercicio para los Indios, e cosa en que no es bien que se ocupen ni lean", demuestra que, efectivamente, no se cumplían, por lo que su circulación era fluida. Prueba de ello es que

Numerosos libros pudieron pasar a América sin trabas ni impedimentos inquisitoriales, incluso muchas obras que a posteriori fueron mandadas recoger o expurgar en los índices inquisitoriales españoles de 1583-1584, 1612 (con los correspondientes apéndices de 1614 y 1628), 1632 o 1640. El tiempo que iba de la delación de la obra y el "proceso" a que era sometida por el tribunal, con las calificaciones de los consultores, y la deci-

«El uso de la imprenta se extendió muy pronto a la Nueva España, pero durante dos siglos permaneció bajo el control estricto de la Corona y la Iglesia Todavía a fines del siglo xvir sólo habia imprentas en la ciudona y la lglesia. Lima, y su producción era casi exclusivamente eclesiástican, Anderson, 1993, p. 96 Cabe señalar que la primera edición de El Quijote en tierras americanas fue hechà en México en 1833 (cf. Carilla, 1951, p. 16). Leonard, 1953, p. 236 afima que "era tan provechoso el negocio de libros que, como en el caso del Quijote, muchas veces se sacaban de las prensas para llevarlos precipitadamente a Sevilla fin de que no perdiesen la salida de las flotas anuales". 
sión de mandarla recoger podía ser de varios años desde su publicación. Esto permitió que bastantes obras atravesaran el Atlántico como parte de los envíos habituales de libreros y mercaderes sin trabas de ningún tipo ${ }^{2}$.

Rodríguez Marín calcula, teniendo en cuenta que faltan parte de los registros de ida de varias naves en 1605 , que el mismo año de publicación de la Primera parte pasaron a América, como mínimo, unos mil quinientos ejemplares de $E l$ Quijote ${ }^{3}$. Varios impresores y libreros españoles del siglo XVII ${ }^{4}$ reconocieron las posibilidades del mercado americano, por lo que la circulación del libro, a pesar de las prohibiciones y de los férreos mecanismos de control instaurados en las prensas virreinales, permitió que su difusión en la Nueva España se erigiera en uno de los rasgos configuradores de la comunidad, al permitir que ésta se apropiara de los modelos vigentes en la cultura libresca. Se trata de una forma de apropiación que trasciende el mismo acto de lectura, incluso de la lectura pública, y que se funda en los valores de recepción añadidos al texto, mediante los que éste alcanza todos los niveles de la: estructura social. Dentro de lo que podríamos denominar, siguiendo a Francisco López Estrada, como «filones literarios que penetran en el conjunto de las Fiestas" ${ }^{5}$, figuran algunos de los motivos, personajes y ambientaciones propios de las materias de ficción más importantes que servirán de antesala a la novela: los libros de caballerías y la literatura morisca, e incluyendo, además, «otros muchos episodios [que] resultan relacionables con los libros de caballerías y con los de otras especies de ficción en que aparecen animales monstruosos, enanos, gigantes, etc. ${ }^{6}$. Así pues, además de los torneos y justas caballerescas que remiten de forma genérica a la tradición cortés medieval, existen otros componentes literarios para trazar los argumentos y el aparato espectacular de la fiesta y que, de forma específica, remiten, por ejemplo, al Cid o al Amadís de Gaula? ${ }^{7}$ Sobre esta relación que se ci-

2 Rueda, 2003, p. 140

${ }^{3}$ Icaza, 1918, p. 112.

${ }^{4}$ Leonard trata en extenso el caso del conde de Sarriá (1953, pp. 223-232) en su novelesca distribución de los primeros ejemplares de El Quijote en el Virreinato del Perú.

${ }^{5}$ López Estrada, 1982, p. 294.

${ }^{6}$ López Estrada, 1982, p. 296.

${ }^{7}$ Ver los ejemplos que propone López Estrada, 1982, p. 294, n. 7 ; p. 295 , n. 8 y n. 10 , y p. 297 , n. 16 . Como comenta el autor, este tipo de fiestas se caracteri- mienta entre los imaginarios de la literatura caballeresca y los de la fiesta, y que se constituye en la tradición que posteriormente enmarcará la presencia festiva de El Quijote, cabe decir que

[...] los libros de caballerías contenían episodios en que aparecían sucesos que tenían el mismo aire que las Fiestas. $Y$ así se establecía un circuito que, por una parte, corría a través de los libros de caballerías (ficción del relato que sólo podía realizarse en la imaginación del oyente o lector de la obra) y, por otra, iba por entre las Fiestas que podían vivirse en la ciudad (realidad del espectáculo que estimulaba el recuerdo y la emoción de la ficción oída o leída).

Lo mismo pudo haberse dicho de la espectacularidad de otras muchas Fiestas; los espectadores gozaban con estas demostraciones porque reconocían en ellas esta relación con la fábula imaginada que así se convertía en una realidad vivida en la tensión regocijada de la Fiesta. Las raíces de la fábula mencionada proceden de un imaginativo medieval ${ }^{8}$.

Así pues, el trasvase de la materia caballeresca al espacio festivo se producirá, inicialmente, por medio de estas celebraciones de corte aristocrático que implican una transposición de los valores del código caballeresco hacia el espacio cortesano y que permiten que la clase nobiliaria se defina de forma especular a través de estos pasatiempos ${ }^{9}$. De

zaban por una serie de rasgos comunes en los que «los nobles interpretaban los papeles caballerescos en las Fiestas y que en su tratamiento hubo un aire deportivo, un "hacer por hacer" que podia ser una manifestación de la "nostalgia de la libre aventura" a que se refiere M. Chevalier, interpretando que los libros de caballerías fueron propios de las clases nobles, con el rey a la cabeza" (López Estrada, 1982, p. 298).

${ }^{8}$ López Estrada, 1982, p. 297.

9 Para el caso novohispano, resulta sumamente interesante observar cómo El Quijote aparece incluso como motivo decorativo, principalmente en el mobiliario. Era frecuente adornar el frente de los bufetes y cajoneras con placas de marfil o hueso que reproducían dibujados en negro los principales personajes de la novela cervantina. Tal es el caso del biombo que reproducimos al final del artículo gracias a las gestiones del Patrimonio Artístico de Banamex, en el que aparecen plasmadas catorce escenas inspiradas en la obra. Los epígrafes titulan asi dichos episodios: «salida de don Quijote de la Mancha; donde le dieron el vino con un cañuto; donde veló las armas; donde lo armaron de caballería; la aventura de los leones; cuando corrió tras de los frailes benitos; la aventura del francés y las mujeres; la penitencia que hizo en Sierra Morena; los molinos de viento; donde venció al caballero de los espejos; cuando mantearon a Sancho; la aventura del puerco jabalí; cuando lo pusieron en el 
forma gradual, podrá observarse cómo estos festejos aristocráticos irán desplazándose hacia la órbita de lo popular y la ensoñación caballeresca pasará a dramatizarse bajo la forma de la mascarada burlesca. La apropiación de los modelos procedentes de los libros de caballería más allá de las clases nobles dirigentes coincide, grosso modo, con la aparición de El Quijote. La parodia de Cervantes supone crear un cambio en el horizonte de expectativas del público receptor, pues la inversión que supone el personaje del Quijote permite que, como argumento festivo, las clases populares puedan reírse con y del personaje. La risa como fenómeno social por antonomasia nos sitúa frente a la presencia de don Quijote y Sancho en varias fiestas populares que tuvieron lugar en España a partir del mismo año de $1605^{10}$ : como informa Pinheiro da Veiga en sus Memorias de Valladolid (1605), dos personajes que, por su aspecto recordaban a los protagonistas cervantinos, intervinieron en una fiesta de toros y cañas con motivo del nacimiento del príncipe Felipe Domingo ${ }^{11}$; en las fiestas de beatificación de santa Teresa de Jesús en Zaragoza $(1614)^{12}$, don Quijote formaba parte de la mascarada que organizaron los estudiantes, así como también en las fiestas que al mismo asunto se solemnizaron en Córdoba (1615); don Quijote también formó parte de los festejos conmemorativos por la solemne publicación que el colegio mayor de Santa María de Jesús hizo en Sevilla del estatuto de la concepción sin mancha de la Virgen María en enero de 1617; en la defensa del mismo misterio, la

caballo clavijo y donde encontró don Quijote a la princesa Micomicona». Para más detailes, ver Rojas Garcidueñas, 1965, pp. 15-65.

${ }^{10}$ El estudio de Lobato, 1994, pp. 577-604, resulta fundamental pues ofrece una detallada y minuciosa visión de conjunto al respecto. Otro de los estudios imprescindibles para el tema es el ya citado de López Estrada, 1982, pp. 291-327. En ambos casos, se encontrará bibliografia al respecto sobre cada uno de los festejos en cuestión, por lo que remitimos a ellos, destacando tan sólo puntualmente aquellos de los que extraemos alguna información adicional o introduciendo aquellos otros que incorporan nuevas noticias sobre alguna de las representaciones.

${ }^{11}$ Los detalles precisos sobre este primer festejo vallisoletano se los debo a los comentarios de Germán Vega García-Luengos, quien me facilita las citas exactas de la Fastiginia, 1973, pp. 124 y 194, en las que queda claro que no se trata de una aparición de los personajes disfrazados como tales, sino que son dos personas que, por su facha, Pinheiro relaciona con los dos protagonistas de la novela.

${ }^{12}$ Cfr. Egido, 1983, pp. 9-78.
Universidad de Baeza, la de Salamanca y en Utrera también involucraron a los personajes cervantinos $(1618)^{13}$. Más allá de la península, un personaje vestido como don Quijote también participó en el desfile con que se recibió en Heidelberg a Federico V, elector del Palatinado, y a su esposa Isabel Estuardo, hija de Jacobo I de Inglaterra $(1613)^{14}$. Otras fiestas tuvieron lugar en Salamanca (1610), París (1618), Barcelona (1633), Burgos (1737), Medina-Sidonia (1740), Barcelona (1759) y Madrid (1863). Por lo que respecta a los virreinatos americanos, hasta la fecha existe constancia de festejos en el de México (1621) y Perú $(1607,1630 \text { y } 1656)^{15}$.

Las circunstancias que motivaron este tipo de celebraciones se hallan ligadas, en algunos casos, a la conmemoración de aniversarios reales y, en mayor grado, a celebraciones de orden religioso, fundamentalmente beatificaciones y festejos a raíz de la publicación del dogma de la Purísima Concepción. En este último caso, la dilogía del caballero "sin mancha» es el motivo que explica la presencia del Quijote en este tipo de pasatiempos festivos. James Iffland, de acuerdo con López Estrada, relaciona estas primeras muestras de recepción de $E l$ Quijote y su inmediata incorporación a la cultura festiva al hecho de que "ya estaban ahí presentes de antemano" ${ }^{16}$. María Luisa Lobato aporta, además, el sustrato procedente de la commedia dell'arte, como "otra de las tradiciones que podrían estar en su origen", pudiendo llegar a pensar que existirian puntos de contacto entre Sancho Panza y el prototipo de criado (Zan Panza di Pegora), por un lado, y del Quijote con la figura del dottore, «uno de los cuatro personajes principales de ese tipo de obras, [que] tenía la mente tan cargada de saber libresco - principalmente mitología clásica, máximas latinas y sentencias legales-, que le resultaba imposible pensar o hablar de una forma senci-

\footnotetext{
${ }^{13}$ Extraemos los datos de Rodríguez Marín, 1911, pp. 50-68.

${ }^{14}$ Leonard, 1953, p. 244.
} ${ }^{15}$ Más adelante podremos observar cómo también pueden incluirse en este
apartado otro tipo de festejos asociados al ámbito universitario y que, para el caso americano, tienen que ver con la obtención del grado de doctor y la celebración de gallos y vejámenes.

${ }^{16}$ Iffland, 1999, p. 55. Del mismo modo, Augustin Redondo también se hace eco de esa "dimensión lúdica" que «han captado inmediatamente los receptore del siglo xvil. En efecto, don Quijote y Sancho, y a veces sus cabalgaduras, aparecen de manera burlesca en numerosas entradas y mascaradas, en bailes y en humildes pliegos sueltos», en Redondo, 2004, p. 53. 
lla y lógica» ${ }^{17}$. En todo caso, como concluye Lobato, lo que parece cierto es que son varias las tradiciones que confluyen en la oposición amo-criado, pues es característica de la cultura occidental la visión dual de la realidad y, para el caso específico «de las mascaradas, los protagonistas solían ser parejas que representaban algún tipo de oposición, presente también en los motes que las acompañaban" ${ }^{18}$.

En este sentido, resulta interesante anotar que el trasvase de fondo que permite la inmediata incorporación de los personajes literarios al espacio festivo virreinal, se confirma en el momento previo de lectuespacio festivo virreinal, se confirma en el momento previa América «los libreros y lectores del Quijote solían enmendar la plana a Cervantes, al par que el título a su obra llamándola Don Quijote $y$ Sancho Panza» ${ }^{19}$. De este modo, podría confirmarse que dichos tipos Sancho Panza»" De este modo, podura festiva popular ${ }^{20}$ y resultarían plenamente identificables, según la «relación agonal entre una figura asociada con los desenfrenados excesos de Carnaval y otra representante del ascetismo, siendo el arquetipo, tal vez, la lucha entre don Carnal y doña Cuaresman ${ }^{21}$.

Tras estas consideraciones generales que apuntan a la inmediata presencia de figuras cervantinas en múltiples festejos populares a partir de 1605 en Europa, cabe señalar algunas peculiaridades para el caso de América, donde rige la distinción entre las mascaradas «serias» y las "facetas» $\mathrm{o}$ "a lo ridículo", la cual descubre, de entrada, la diferencia-

${ }^{17}$ Lobato, 1994 , pp. 580-581.

${ }^{18}$ Lobato, 1994, p. 581.

19 Rodríguez Marín, 1911, pp. 34-35.

20 óp Cervantes hubiesen tenido una preexistencia en la vida de la época y que su preCervantes hubiesen tenido una reconocimiento. Así fue cómo la fama de don Quijote sentación literaria fuese un reconocimiento. Así fue como la fama de don Quijote se vio extendida por esta concurrencia. Es evidente que el caballero, Sancho y

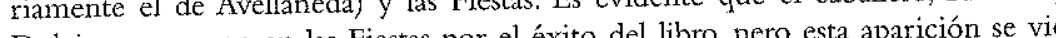
Dulcinea aparecen en las Fiestas por el exito del libro, pero favorecida por la peculiar condición de estos personajes, que fueron muy pronto asimilados por la vorágine lúdica que desencadenan las Fiestas. Pudiera ser tam bién que lo condición de loco que Cervantes atribuye al mismo comienzo de bién que la condición de loco que Cervantes atribuye al mismo conienzo del libro a su personaje cuando se refiere a que vino a perder el juicio $(I, 1)$ favoreciese el que pronto fuese a parar su figura a las mascaradas, junt

cos de turno, y que con ción entre un circuito aristocrático y otro de carácter más popular. Según Romero de Terreros ${ }^{22}$, la mascarada fue introducida en la Nueva España por Martín Cortés, marqués del Valle (1532-1589). Las Noticias históricas de la Nueva España de Suárez de Peralta precisan sus formas originales:

Dieron también en hacer máscaras, que para salir a ellas no era menester más de concertallo en la mesa y decir: «esta tarde tengamos máscaran y luego se ponía por obra y salían disfrazados cien hombres de a caballo y andaban de ventana en ventana hablando con mujeres y apeábanse algunos y entraban en las casas de los caballeros y mercaderes ricos, que tenían hijas o mujeres hermosas, a parlar. Vino el negocio a tanto que ya andaban muchos tomados del diablo, y aun los predicadores lo reprehendían en los púlpitos; y en habiendo máscara de disfrazados se ponían algunos a las ventanas con sus mujeres y las madres con sus hijas para que no las hablasen libertades; y visto que no podían hablarles, dieron en hacer unas cerbatanas largas, que alcanzaban con ellas a las ventanas y poníanles en las puntas unas florecitas y llevábanlas en las manos y por ellas hablaban lo que querían ${ }^{23}$.

Leonard puntualiza que las máscaras a lo serio y a lo faceto solían combinarse y que, tratándose del espectáculo público más común, la mascarada consistía en uun desfile de personas disfrazadas con diversas indumentarias, y que, llevando máscaras peculiares, desfilaban por las calles de día o de noche, a pie o montadas en caballos y otros animales. Después del anochecer encendían antorchas, prestando así a la ciudad insólita iluminación. Representaban personajes históricos, mitológicos o bíblicos, los dioses de religiones primitivas, planetas astrológicos, las alegorías de las virtudes, de los vicios, o de otras abstracciones; y casi cualquier criatura fantástica, real o imaginaria, era novedad bien recibida. Las personificaciones representaban hombres, ideas o cosas que

22 Romero de Terreros, 1918, p. 7.

${ }^{23}$ Súrez de Peralta 1878, pp 193-195. En el mismo capítulo, el autor también atribuye al marqués la costumbre de introducir el brindis y el juego en la Nueva España, fijando las reuniones en casa del virrey como el lugar donde se acordaba la celebración de mascaradas: «El marqués hacía plato a todos los caballeros y en su casa se jugaba, y aun se dio en brindar, que esto no se usaba en la tierra ni sabían qué cosa era, y admitióse este vicio con tanta desorden como diré" (p. 194). 
variaban desde lo sublime hasta lo ridículo, desde lo exquisito hasta lo grotesco, con formas que iban desde lo más venerable hasta lo más satírico. Para el público iletrado la mascarada era como una revista viva que presentaba ante sus ojos una semejanza de las cosas reales o imaginarias; que instrúa, divertía, entretenía y, a menudo daba expresión a sus estados de ánimo, a su reverencia y a su resentimiento» ${ }^{24}$.

Dicha mezcla entre lo serio y lo faceto que se apunta para las mascaradas virreinales, es algo inmanente al mismo género ${ }^{25}$ pues la fiesta barroca, en general, se define por su carácter envolvente, a partir del cual la ocupación del espacio público gracias a una circunstancia extraordinaria permite la participación activa de todos los estratos sociales, ya sea como espectadores que miran (clases populares) o como participantes mirados (clases dirigentes). A tal efecto resultan ilustrativas las palabras del relator de la mascarada quijotesca celebrada en Barcelona en 1633: «estylo es desta tierra tomar estos assuntos o otros semejantes con que, unido lo ridículo y lo grave, lo verdadero y lo apócrifo, forman una fiesta entretenida, alegre y grandiosa ${ }^{26}$. La fiesta barroca debe unir, pues, lo ridículo y lo grave ya que sólo así podrá ser entretenida, alegre y grandiosa, es decir, de este modo ejercerá su función propagandística al involucrar a todos los estamentos participantes mediante el entretenimiento festivo. Aunque como toda forma lúdica, la fiesta barroca se halla regulada por una serie de mecanismos. Como afirma Johan Huizinga:

El juego se aparta de la vida corriente por su lugar y por su duración [...]. Se juega dentro de determinados límites de tiempo y de espacio. Agota

\footnotetext{
${ }^{24}$ Leonard, 1976, p. 177.

${ }^{25}$ Buezo, 1993, propone un sugerente esquema para definir a la mojiganga como una máscara en la que se mezcla lo ridículo y lo grotesco de forma gradual: 1. Máscara seria $\rightarrow 2$. Introducción de elementos bufos $\rightarrow 3$. Máscara mixta $\rightarrow$ 4. Máscara ridícula (p. 31). Si pensamos en la evolución de las fiestas de asunto quijotesco bajo estos términos, podemos observar que se cumple en la evolución que los convierte de divertimentos cortesanos - a los que Irving se refiere para la Nueva España como máscaras a lo serio- en mascaradas burlescas - definidas por Leonard como a lo faceto-, coincidiendo con la publicación de El Quijote y, sobre todo, a raíz de la aparición de la segunda parte en 1615 .

${ }^{26}$ La relación fue inicialmente publicada por Givanel Mas, 1915. Citamos a
} partir de López Estrada, 1982, p. 305. su curso y su sentido dentro de sí mismo [...]. Dentro del campo de juego existe un orden propio y absoluto. He aquí otro rasgo positivo del juego: crea orden, es orden. Lleva al mundo imperfecto y a la vida confusa una perfección provisional y limitada. El juego exige un orden absoluto ${ }^{27}$.

Por ello, la fiesta como una manifestación colectiva que introduce una cesura en la vida cotidiana permanece sometida a las directrices que dicta el poder establecido y, precisamente, el orden en la etiqueta condiciona su eficacia como pasatiempo. La fiesta barroca se convierte en un espacio privilegiado en el que por medio de la invitación a la risa y bajo el pretexto de consolidar el orden sociopolítico vigente se consigue crear una representación espectacular del ideal de poder. Fernando Rodríguez de la Flor se refiere a esta representación exhibitoria del poder mediante la fórmula de «Efímero de Estado». La expresión supone identificar «al poder de la sociedad cortesana con la praxis del espectáculo, con la decisión de organizar una representación que es ante todo pública, que se celebra ad oculos» ${ }^{28}$. La consideración de la fiesta como espectáculo dióptrico (es decir, ofrecido a los ojos e ideado desde la perspectiva de los espectadores) presupone que el poder es ante todo simbólico y que, inherente a la pompa, su aparato representacional encuentra en la fiesta el único lugar posible donde puede realizarse ${ }^{29}$.

Así pues, considerando la necesaria mezcla entre lo serio y lo faceto, y asentadas las bases que definen un código establecido para cada uno de los participantes en la fiesta pública, podemos distinguir una diferencia esencial en la puesta en escena entre la máscara o mascarada y la mojiganga, a pesar de que se trata de voces que en muchos casos se encuentran cruzadas - y más en el caso de algunas de las apariciones festivas de personajes de El Quijote-: mientras la primera se define por ser un «lento, armonioso y opulento despliegue de vestidos y joyas a caballo", la segunda se entiende como una "procesión", también a caballo, sin "orden" y llena, por tanto de "confusión" con trajes «muy peregrinos»"

${ }^{27}$ Huizinga, 1999, pp. 22-23.

${ }^{28}$ Rodríguez de la Flor, 2002 , p. 162.

${ }^{29}$ Sobre la reflexión en torno a la realización simbólica del poder, ver Bordieu, 1987 y Subirats, 1999.

${ }^{30}$ Buezo, 1993, p. 38. 
vestuario de su puesta en escena, nos interesa partir de las variantes de mojiganga callejera, entendida como procesión festiva, para establecer los rasgos que definen las mascaradas con presencia de personajes quijotescos ${ }^{31}$. Según dichos parámetros, podremos encuadrar las mascaradas americanas en torno a El Quijote bajo tres espacios festivos: el cortesano, el urbanístico-popular y el estudiantil.

En el apartado cortesano, incluimos las dedicadas a los reyes por las autoridades y la nobleza virreinal que pueden desarrollarse en los espacios públicos habituales para la fiesta. En este epígrafe se sitúan los festejos que don Pedro de Salamanca organizó en el campo minero de Pausa para conmemorar el nombramiento del marqués de Montesclaros como nuevo virrey de Perú (1607), que constaban de una mascarada en la que don Luis de Gâlvez representaba el papel de don Quijote ${ }^{32}$. El siguiente fragmento describe el torneo entre don Quijote y Baco, que este último terminará ganando para ofrecer el premio a una criada vieja:

A esta ora asomó por la plaça el Cauallero de la Triste Figura don Quixotte de la Mancha, tan al natural y propio de cómo le pintan en su libro, que dio grandissimo gusto berle. Benia cauallero en vn cauallo flaco muy pareçido a su rrozinante, con vnas calçitas del año de vno, y vna cota muy mohoza, morrion con mucha plumeria de gallos, cuello del dozabo, y la mascara muy al proposito de lo que rrepresentaba. Aconpañabanle el cura y el barbero con los trajes propios de escudero e ynfanta Micomicona que su corónica quenta, y su leal escudero Sancho Panza, graçiossamente bestido, cauallero en su asno albardado y con sus alforjas bien proueydas y el yelmo de Manbrino, lleuáuale la lança, y tanbien siruió de padrino a su amo, [...] y presentandosse en la tela con estraña risa de los que miraban, dio su letra, que dezia:

Soy el avdaz don Quixo-

$\mathrm{Y}$ maguer que desgraçia-

Fuerte, brabo y arrisca-

${ }^{31}$ Son cinco las variantes del género, según la tipología propuesta por Catalina Buezo: mascarada de autoridades, nobles, caballeros y miembros de la realeza; mascarada gremial; mascarada eclesiástica; mascarada estudiantil y mascarada del vulgo (1993, p. 33), que asimismo surgen de la consideración de cinco espacios de representación: cortesano, urbanístico-popular, estudiantil, eclesiástico y taurino (1993, p. 35).

32 Cfr. Rodríguez Marín, 1911, pp. 74-94, quien en el apéndice reproduce íntegra la Relación de las fiestas (pp. 97-118).
Su escudero, que era vn hombre muy graçiosso, pidió licençia á los jueçes para que corriesse su amo y pusso por preçio vna dozena de çintas de gamussa, y por benir en mal cauallo y azerlo adrede fueron las lanças que corrió malísimas, y le ganó el premio el dios Baco, el qual lo preçentó [a] vna vieja, criada de vna de las damas. Sancho echó algunas coplas sentó [a] vna vieja, criada de vna de las dan berdes no se refieren ${ }^{33}$

Es interesante notar cómo el prototipo de este tipo de festejos nobles sigue las formas del espacio cortesano, aunque al mismo tiempo incorpora elementos característicos del medio popular. Es decir, a la representación caballeresca de correr la lanza ${ }^{34}$ se une el énfasis en su puesta en escena ridícula: desde el vestuario hasta el contraste entre las parejas Quijote/Sancho, princesa Micomicona/criada vieja y Quijote/Baco. En este apartado constan también los festejos que se organizaron en Lima para la conmemoración del nacimiento del príncipe Baltasar Carlos $(1630)^{35}$

El segundo espacio festivo en el que transcurren las mascaradas quijotescas en los virreinatos americanos es el urbanístico-popular, donde se suceden las festividades organizadas por los gremios de la ciudad, dedicadas a los reyes o a algún santo patrón. Para hacernos una iden cómo eran este tipo de festividades en América, podemos parir de le cómo se manejaba la participación gremial en las celebraciones. Pilar Gonzalbo Aizpuru reproduce algunos datos acerca del reparto presupuestario y de las multas impuestas a quienes no cumplían con lo establecido:

En cada ocasión, el Ayuntamiento desembolsaba cantidades proporcionales al número y calidad de las actividades programadas; la brillantez del jolgorio dependía en gran parte de la disposición de los regidores y del jolgorio dependia en colaboración econóca de la situación de las arcas de la ciudad o de la colaboración económica
del propio virrey. La ciudad costeaba pólvora, cera, salarios y vestidos de

${ }^{33}$ Rodríguez Marín, 1911, pp. 110-112.

${ }^{34}$ Cfr. Coello Ugalde, 1987.

35 Cfr. López Estrada, 1982, p. 294, n. 6; Lasso de la Vega, 1942, p. 362 y Suardo, 1936 pp. 143-144: «delante del carro [de Marte] yba la victoria muy bien ade1936, rezada en un cacompañaron, a lo graciosso, los del mundo, antiguos y modernos, tambien le acompanaron, a lo graciosso, los entre ellos don Quixote y Sancho Panza». 
los músicos. Las varas, puyas y arandelas y los gozetes destinados a los juegos de toros y cañas, se conservaban como propiedad del cabildo, que así evitaba repetir los mismos gastos anualmente. Los gigantes y cabezudos requerían de renovación de vestuario cada cierto tiempo; y los premios de certámenes y concursos eran a veces donativo de instituciones. [...]

Aunque los gastos se cargaban a las rentas que como propios disfrutaba la ciudad, también se recurría a la imposición de multas contra quienes negaban su participación. [...] Las cofradías que no participaban en los desfiles y procesiones que exigían su presencia debían de pagar treinta pesos de oro de minas; y la recaudación podía ser más sustanciosa cuando la cofradía se presentaba pero faltaban algunos de sus miembros; en tales casos, cada artesano faltante pagaba diez pesos individualmente ${ }^{36}$.

En este ámbito festivo, situamos la máscara que el gremio de la platería de México, compuesta por Juan Rodríguez Abril, hizo en honor de la beatificación de san Isidro $(1621)^{37}$. Si tenemos en cuenta las obligaciones impuestas a los distintos gremios novohispanos y que concretamente el de plateros era uno de los más prestigiosos de la ciudad de México ${ }^{38}$, podremos intentar una reconstrucción de dicha máscara. De la descripción del cortejo en el que participó don Quijote, entresacamos el siguiente fragmento:

Delante de sí, por grandeza y ornato, todos los caballeros andantes autores de los libros de caballerías, Don Belianís de Grecia, Palmerín de Oliva, el caballero del Febo, etc., yendo el último, cono más moderno, Don Quijote de la Mancha, todos de justillo colorado, con lanzas, rodelas y cascos, en caballos famosos; y en dos camellos Mélia la Encantadora y Urganda la desconocida, y en dos avestruces los Enanos Encantados, Ardian y Bucendo, y últimamente a Sancho Panza, y doña Dulcinea del

${ }^{36}$ Gonzalbo Aizpuru, 1993, p. 30.

${ }^{37}$ Cfr. González Obregón, 1999, pp. 270-271 y Leonard, 1976, pp. 177-179.

${ }^{38}$ Según Gonzalbo Aizpuru, 1993, p. 35, el gremio de plateros tenía el lugar preferente, junto al palio donde se exhibía la custodia, en la fiesta del Corpus y, además, era el encargado de portar la imagen de san Hipólito, patrón de la ciudad, en la misma procesión. Además, este gremio se distinguió por ser uno de los más férreos defensores del dogma puesto que sus patronos principales eran san Eloy y la Purísima Concepción, lo que hizo que en todas las fiestas concepcionistas participaran con lujosas donaciones. Zurián, 1995, describe, como ejemplo, las fiestas que el gremio de plateros organizó el 8 de diciembre de 1648 con motivo de la apertura de la capilla de los Plateros, pp. 82-83.
Toboso, que a rostros descubiertos, los representaban dos hombres graciosos, de los más fieros rostros y ridículos trajes que se han visto: llevaba por todos cuarenta hombres ${ }^{39}$

En este tipo de celebraciones destaca el efecto grotesco de la puesta en escena, al señalar que tanto Sancho Panza como Dulcinea son representados por dos hombres graciosos, de los más fieros rostros y ridículos trajes. El travestismo es en este marco festivo uno de los elementos cómicos preferidos por el público. Muestra de todo ello son las prácticas que surgen alrededor del carnaval, puesto que

Sólo esporádicas disposiciones represivas, de fecha tardía, nos hablan de ocasionales desórdenes en la ciudad de México; a todos los grupos populares, indistintamente españoles y castas, se atribuía el uso de ropas propias del otro sexo y de trajes talares de religiosos durante los tres días de Carnestolendas ${ }^{40}$.

Finalmente, el tercer espacio festivo, el ámbito estudiantil, incluye las mascaradas organizadas por colegios y universidades; aunque deben contemplarse, dentro del calendario festivo ordinario, las organizadas para la defensa del dogma de la Purísima Concepción y las surgidas a raíz de la obtención del grado de doctor que acompañaban a la celebración de gallos y vejámenes. Sobre este tipo de paseos ridículos y vítores, sabemos que también se realizaban, además de en el momento de obtención del grado de doctor, en el examen de oposición a cátedra:

En las universidades de México y Guatemala al opositor triunfante le estaba prohibido salir en paseo "ridículo» de vítor, bajo pena de multa

39 Entresacamos el fragmento de la Relación que reproduce como apéndice Romero de Terreros, 1918, pp. 30-39.

${ }^{40}$ Gonzalbo, 1993 , p. 32 . Aunque de hecho no se trata de una práctica que se limite al Carnaval, ya que este tipo de travestismo festivo era frecuente, tal y como se demuestra con las celebraciones del último de los aniversarios de Carlos II en 1700 en la ciudad de México. Robles, 1946, vol. 3, p. 129, anota que: «Salió otra máscara con representación del mundo al revés, los hombres vestidos de mujeres y las mujeres de hombres; ellos con abanicos y ellas con pistolas; ellos con ruecas y ellas con espadas: el carro vestido gallardamente con un retrato de san Juan de Dios, y un garzón ricamente adornado que recitaba una elegante loa". 
Pasados ocho días de haber obtenido la cátedra, sí podían salir en paseo grave y decente, y en caso de no haber tomado posesión de la misma, tenía que ir a la universidad, donde el rector le daba posesión ante el secretario $^{41}$.

Para el caso de la Universidad de San Marcos en Lima, nombre que tomó a partir de 1571, Diego de León Pinelo publicó las Semblanzas de la Universidad de San Marcos, traducidas del latín por Luis Antonio Eguiguren, Alegato apologético en defensa de la Universidad limense (Lima, 1648), de la que extraemos las siguientes noticias sobre las celebraciones en la obtención del grado de doctor:

Vencido ya el rigor de los argumentos, hechas las primeras solemnidades, seguro de la licenciatura, el laureando asciende al caballo para el triunfo y la pompa literal. Los trompeteros dan señales con las trompetas, no para que amenazador sonido hiera los oídos, sino con clamor suave y festivo. Precede la bandera universitaria puesta en hasta. Los Doctores y Maestros marchan a caballo adornados con las insignias de los sabios [...]. Adornados con fieros arreos (solamente el caballo entre todos los animales, según dice Plutarco, 2 simpos, es parte en la lucha y en la victoria y es animal digno de un hombre libre) se dirigen a la casa del rector, quien con los senadores de la Cancillería y los principales miembros de la Academia esperan la agradable visita.Y así el mústico cuerpo de los sabios y de las ciencias, como prado risueño florido de varios colores, con el acompañamiento de buena parte de los ciudadanos discurre por las calles de la ciudad, por la plaza real, anunciando fuera de la Academia la fiesta. Finalmente, restituido el Rector a su propia casa, los demás doctores en forma solemne acompañan al laureado y dispersándose se van. Todo esto se hace la víspera. Rayando el día, después que aparece el sol. [...] Tomadas las insignias del caballo [...] desciende, hiriendo la tierra con las espuelas de oro, es hecho noble con un título civil, con no menor título que el de la familia y la prosapia se enriquece. El laureando sube al teatro, como un soldado el muro, para tomar el birrete, que es a manera de corona, [...].

Sigue la honrosa y pública alegría del doctorado en la Catedral Metropolitana, en el Altar y Capilla de N. S. La Antigua, alumbrada continuamente con la luz de una gran lámpara de plata [...]: Este día es deseadísimo por todas las gentes, como en otro tiempo por los siervos de las saturnales. [...] Un doctor o maestro con sus chistes, ni venenosos ni

${ }^{41}$ Rodríguez Cruz, 1992, pp. 58-59. procaces, hace florida y grata la fiesta; porque el fin no es otro sino la alegría y la hilaridad: «la laurea apetece la fiesta y el llanto del Doctor». Esta antigua costumbre, a la cual aquel Luciano, apellidado siempre el blasfemo, dice cara cómica en vez de jocosa, alegre y límpia; Rodigin la encuentra usada entre los atenienses en el tiempo de las vendimias, lect. Antiq. lb. 6 c. 17 , entre los nobles y Ateneo testifica lb. 2 c. 1 que ocurría en las escenas de los sabios ${ }^{42}$.

Por lo que respecta a la Universidad de México, ésta tuvo como patronos originales a san Pablo y a santa Catalina mártir, aunque más tarde pasó a ser la Inmaculada, para cuya celebración se acordaron lucidos festejos públicos. El cabildo de la ciudad organizó por primera vez la celebración de la Inmaculada en 1618. El claustro universitario determinó exigir a todos sus catedráticos el juramento de fidelidad al dogma, a pesar de que los dominicos, amparándose en la doctrina de santo Tomás, se resistieron ${ }^{43}$. Ante la respuesta favorable del papa a la solicitud de celebrar la fiesta

respondió el cabildo con la organización de juegos de cañas y corridas de toros, con un gasto de 6000 pesos que se tomarían del sobrante de las alcabalas. En esta primera vez los festejos tuvieron lugar los días 17 , 19 y 20 de diciembre. A partir de 1653 , la universidad decidió celebrar anualmente a la Inmaculada, a imitación de las universidades españolas. Eligió para ello el 19 de enero, aunque circunstancialmente podía trasladarse a otra fecha próxima. Con motivo de la celebración se convocaban certámenes literarios, se ponían colgaduras, había misas cantadas y predicación de sermones alusivos y se prendían "grandes y costosos fuegos» ${ }^{44}$.

Desde el siglo xvi, gracias a la vinculación entre las universidades de Salamanca y Lima, fueron comunes los traspasos de hábitos estu-

${ }^{42}$ León Pinelo, 1949, pp. 71-77. Los fragmentos proceden del capítulo XII: "Pompa triunfal del doctorado".

${ }_{43}$ Cfr. Gonzalbo Aizpuru, 1993 , p. 36.

${ }^{44}$ Gonzalbo Aizpuru, 1993, pp. 36-37. También Rodríguez Cruz, 1992, comenta lo siguiente: «En los libros de claustros encontramos muchos ecos de la celebración de estas fiestas, principalmente de la Inmaculada, misterio del que la universidad fue devotísima, como las demás hispánicas, a imitación de Salamanca, y sobre todo después de que se impuso, en la primera mitad del siglo XVI, de un modo rigurosamente obligatorio y constitucional el juramento de defenderlo, del que no podían excusarse catedráticos y graduados, y no podía faltar tampoco en 
diantiles entre los centros de España y América. De ahí se extendieron a la de México y Santo Domingo y, más adelante, a las de Charcas, Quito y Guatemala ${ }^{45}$. Sobre el nacimiento de la Universidad de México, cabe decir que Felipe II expidió la Real Cédula Fundatoria el 21 de septiembre de 1551, a instancias de los ruegos del obispo de la ciudad de México y del virrey, don Antonio de Mendoza, para que «los naturales e hijos de los españoles fuesen instruídos en las cosas de la santa fe católica y otras facultades». Esta Real Cédula ordena la fundación de la universidad, concediéndole «los privilegios, franquicias y libertades que tenía la Universidad de Salamanca»" ${ }^{46}$. Por lo que respecta al Virreinato del Perú, la cédula fundatoria de la Universidad de Los Reyes fue expedida en Valladolid el 12 de mayo de 1551 y «la establece con los mismos privilegios de la Universidad de Salamanca, pero al igual que en el caso de la Universidad Mexicana, y de todas las demás universidades hispanoamericanas fundadas en la época, se fijan limitaciones; una de las cuales fue no gozar de jurisdicción privativa ${ }^{47}$. Parece que la universidad inició sus clases en 1553 , según una tarja que pendía de una de las paredes del Aula Magna ${ }^{48}$. La Real Cédula, consignada por Felipe II, que le concedía los mismos privilegios que la universidad salmantina data del 31 de diciembre de $1531^{49}$. Entre las reformas a las constituciones universitarias del virrey Juan de Mendoza y Luna, marqués de Montesclaros, impresas en Madrid en 1624, destacan las que propugnan que los catedráticos perderían sus permisos si no defendían el dogma de la Inmaculada Concepción, así como que el vejamen en los grados de doctor lo ha-

la toma de posesión de los cargos. Sabemos que Salamanca fue la primera en establecerlo y como la monarquía la apoyó y le dio las gracias por ello, y más tarde al hacerse extensivo a las universidades hispanoamericanas fue recogido en 1 Recopilación de Indias" (p. 164). Ver también Carreño, 1963, vol. 1, pp. 130 131.

${ }^{45}$ Lobato, 1994, p. 594. Para una visión de conjunto, ver las conclusiones finales sobre México, Santo Domingo y Lima en Méndez Arceo, 1952, pp. 101104, así como Rodríguez Cruz, 1992, en especial las pp. 17-33.

${ }^{46}$ Madrazo, 1980 , p. 32. Los cursos se inauguraron solemnemente el 25 de enero de 1553, y se iniciaron el 3 de junio del mismo año. La Real Universidad de México obtuvo el título de Pontificia a partir de una bula del papa Clemente VII, expedida el 7 de octubre de 1597 (p. 33).

4? Madrazo, 1980, p. 39.

${ }^{48}$ Rodríguez Cruz, 1992, p. 115

${ }^{49}$ Rodríguez Cruz, 1992, p. 125 ría el doctor más moderno de la facultad ${ }^{50}$. Francisco de Borja y Aragón, príncipe de Esquilache, «añadió el juramento de creer y enseñar el misterio de la Inmaculada Concepción que debían hacer los graduados, lo mismo que el juramento o profesión de fe, de acuerdo con el concilio de Trento y la bula de Pío IV ${ }^{51}$.

Las fiestas organizadas en defensa del dogma de la Virgen fueron sucediéndose en las universidades americanas, tal y como sucedía en las de la metrópoli y, como hemos visto, por influencia directa de la Universidad de Salamanca. Tal es el caso de la Universidad de Lima, que en 1656 «divulgó en carteles con dos días de anticipación sobre los actos y pregonó la víspera del jueves 14 de diciembre de 1656, que habría una Máscara ofrecida al Patronazgo fundado en el Misterio de la Purísima Concepción de la Virgen María» ${ }^{52}$.

Por lo que respecta a las ceremonias celebradas por la obtención del grado de doctor, nos centraremos en el vejamen de don Félix de Luna (México, siglo XVInI) ${ }^{53}$ y en el dedicado al Dr. Antonio Coronel $(\mathrm{Cuzco}, 1685)^{54}$, en el que tan sólo aparecen tres menciones aisladas a

\section{${ }^{50}$ Rodríguez Cruz, 1992, p. 126.}

${ }^{51}$ Rodríguez Cruz, 1992, pp. 126-127. Zurián, 1995, pp. 71-72, lo resume de la siguiente forma: "Ya en el III Concilio Provincial de Lima, convocado en el año de 1582 por Toribio de Mogrovejo, se señaló como fiesta de precepto para los españoles el día de la Inmaculada Concepción. Lo mismo se prescribía en la Consueta o Costumbrero de la Iglesia de Lima. El III Concilio Provincial de México, celebrado en 1585, al hablar de los días festivos, hacía hincapié en que todos los fieles de esos reinos, exceptuando los indios, tenían obligación, bajo pena de pecado mortal, celebrar como festivo el día de la Concepción sin mancha de Maria».

52 Lobato, 1994 , p. 578 . Cfr. el fragmento de dicha relación reproducido en las pp. 598-599, donde se aprecia una detallada descripción de don Quijote, Sancho y Dulcinea, así como de su vestuario.

${ }^{53}$ Vejamen por don Félix Luna, Colección Gómez de Orozco, n. ${ }^{\circ} 112$ en el Archivo de la Biblioteca Nacional de Antropología e Historia. No podemos precisar la fecha, aunque seguramente puede localizarse a mediados del siglo xVIII. Cfr. Mendoza, 1951, p. 40

54 Vexamen que dio el Dor. Dn. Jacinto de Hevia Bustos, cura y vicario de la doctrina de Acobamba en el abispado de Huamanga, al Dr. Dn. Antonio Coronel, cura $\gamma$ vica rio de Moquegua en el obispado de Arequipa, Cuzco. Año de 1685. Se halla depositado en la Biblioteca Nacional de Lima, bajo el rubro de Papeles varios y signatura número 165 , fol. 243 . Nos ha sido imposible consultar dicho documento, por lo que trabajamos a partir de la edición de Eguiguren, 1949, pp. 19-58. 
El Quijote. La primera alusión que aparece en el vejamen limeño ejerce una inicial función caracterizadora, cuyo propósito es delimitar el marco sobre el que trazar la descripción del personaje vejado. La referencia quijotesca sirve para connotar metonímicamente su origen noble, resaltar su formación académica y, por tanto, su inclinación a la lectura:

Ya se sabe que nuestro doctorando nació en la ciudad ilustre de Arequipa, con que se sabe también que se trae de suelo entre sus gracias el don de la caballería. Precia tanto de noble que viniendo en la ocasión presente a graduarse, donde quiera que hacía noche introducía hospite insa. lutato el grado de parentesco que tiene con el señor Marqués su primo, y con esta veleta caminaba viento en popa su rumbo. Venía en litera muy a lo título y presumiendo (con algún fundamento) un mozo de corbata, que tan extraña idea, sería alguna fechoría o aventura de don Quijote, se le hizo [en]contradizo, con pretexto de saber cuyo era tan loco carruaje ${ }^{55}$

La segunda mención amplía los rasgos apuntados en la primera descripción de don Diego Coronel y le presenta llevando en la mano un ejemplar del libro de Cervantes, junto a otros atributos que confirman la fisonomía de su primera aparición, el escudo para designar su nobleza y la borla de doctor alusiva a su formación académica: "Un escudo o pavez en la una mano, y en la otra un libro de don Quijote y sobre éste la borla de doctor» (p. 41). La última de las menciones de $E l$ Quijote ya no sirve para caracterizar al personaje, sino que alude a una situación en la que se ve envuelto el graduando. En esta ocasión, el adjetivo quijotesca aparece como sinónimo de mojiganga:

Al volver del colegio en su Arequipa encontró en una calle a unos muchachos que iban sosteniendo (como lo han costumbre) una manga de Pavellón, a cuyo abrigo salían a oúr misa unas mujeres descalzas (sin ser recoletas), así que nuestro graduando vio aquella mojiganga, que juzgó aventura de don Quijote, y dando a los muchachos de coces y puñadas desparpajó a la gente, y el campo ya por suyo condujo a las mujeres en la manga y prorrumpió diciendo:

${ }^{55}$ Tomamos la ya citada edición de Eguiguren, 1949, de la que hemos modernizado la ortografia y la sintaxis, p. 34 . A partir de ahora indicaremos entre paréntesis la página.

\author{
«En aquesta mojiganga \\ que va en forma de cuartel \\ sólo toca a un coronel \\ el poder de llevar la manga" (p. 44)
}

Por lo que respecta al vejamen de don Félix Luna, a partir de la inicial idea de que todo el curso académico ha sido un sueño, las burlescas alusiones a El Quijote sirven para ejercer una invectiva en contra de otros universitarios presentes: José Antonio Rodríguez, José Manuel Mauriño, José María Bocarando y. José Athanacio Aedo. El objetivo del vejamen, como apunta Abraham Madroñal, consiste en "ponderar los defectos del graduando con la finalidad de contrarrestar la soberbia que en un día como ése se apoderaba de él. No era la finalidad del vejador decir los posibles defectos reales del graduando, sí exagerar aquellas lacras, tanto físicas como morales, que a sus ojos se le ocurrían. Para equilibrarlo, después de esta sarta de alusiones, algunas más que subidas de tono, otro concursante ofrecía un poema (a veces también un texto en prosa), éste en serio, según se solía advertir, donde se ponían de manifiesto las virtudes del graduando" ${ }^{56}$.

El fragmento que reproducimos a continuación en el apéndice contiene los procedimientos humorísticos y de burla, característicos del género. José Antonio Rodríguez ejerce de Quijote, José Manuel Mauriño de Sancho Panza, Athanacio Aedo de Dulcinea y José María Bocarando de dueña Dolorida. Además del travestismo habitual que insiste en la fealdad del hombre que se viste de mujer, aparecen varios chistes a partir de la inversión paródica de ciertas referencias a la novela. Tal es el caso, por ejemplo, del fragmento en el que Rodríguez, como Quijote, ridiculiza a Mauriño en su papel de Sancho, por bobo, rústico y $\sin$ capacidad para hablar en público. La burla se construye a partir del apelativo de Bato que Rodríguez le dedica a Mauriño. Además de la burla por la supuesta tartamudez que conlleva la misma alusión y, por tanto, a la incapacidad oratoria que Rodríguez le achaca a Mauriño, la referencia contiene, con toda seguridad, alguna alusión al contexto universitario del momento y a la representación de pastorelas navideñas. Son habituales también en el fragmento la yuxtaposición desmesurada de refranes, y, en definitiva, estrategias para 
caricaturizar a los personajes cervantinos. Todo ello en un ambiente de chanzas y burlas en el que se superponen diálogos dramáticos, música y baile.

La presencia de los personajes cervantinos en este tipo de mascaradas universitarias celebradas en los vejámenes de grado permite pensar en una lectura estudiantil, también en los virreinatos americanos, de El Quijote como novela de burlas. El contexto vejatorio de la ceremonia de graduación concuerda con el horizonte de expectativas de la novela entre los universitarios, por lo que, más allá de fiestas extraordinarias y celebraciones puntuales, El Quijote encaja en los propósitos burlescos del vejamen de grado, al mismo tiempo que permite que, tanto mirantes como mirados, puedan acceder a la chanza, pues se trata de referentes que fueron muy pronto asimilados, en palabras de López Estrada, por la vorágine lúdica - ya sea porque existían de antemano o se tratara de un reconocimiento a la creación literaria de Cervantes.

\section{APÉNDICE}

«Máscara de mojlganga sobre el Quijote en el Vejamen de Don félix Luna», Biblioteca Nacional de Antropología e Historia, Colección Gómez de Orozco 112 , pp. 17v $21 \mathrm{R}^{57}$.

Cayó el telón, cubrióse el teatro y desde luego se me figuró una máscara o mojiganga que componían don José Antonio Rodríguez, don José Manuel Mauriño, don José María Bocarando y don Athanasio Aedo.Traían su danza que formaban don Lorenzo Pérez, don Francisco Mendivil, don Miguel Arenal, don José Manuel Villarelo y don José María Aguilar, y al compás de un órgano y un violín que tocaban don Martín Mauleon y don Mariano Gallegos. Unos daban pasos concertados y otros estaban concertados en no dar paso.

Venía don José Antonio Rodríguez a caballo en la misma figura que pinta el famoso Miguel de Cervantes al Ingenioso Hidalgo don Quijote de la Mancha, bien que el mismo Rodríguez aunque no tenía lo ingenioso de este héroe, tenía lo Quijote. Como digo, pues, en mi sueño traía su lanza y escudo, con la celada cubierto el rostro y la cabalgadura, cuyos lomos oprimía tan flaca, que más de cuatro zopi$\operatorname{lote}^{58}$ la miraban con ojos tiernos, creyendo que a cada paso caería muerta, pues tan al vivo representaba un esqueleto. Don José Manuel Mauriño montaba un jumento que me figuró al rucio de Sancho Panza imitando en todo a este leal escudero, pues aun la máscara con que cubría la cara era muy semejante a la que se nos pinta en la historia $y$, aunque no es tonto, en las producciones geniales que tiene, puede apostarlas al mismo Sancho Panza. En una ocasión se le propuso este enigma para que lo desatara:

\section{¿Quién es el león coronado, vario el color del vestido,}

${ }^{57}$ El manuscrito se conserva en general en buen estado, aunque algunos agujeros dificultan la lectura. Para esos casos y en otros en los que dudamos en la transcripción, hemos utilizado los corchetes.

${ }_{58}$ «Del nahua tzopilotl. Am. Cen. y Méx. Ave rapaz diurna que se alimenta de carroña, de $60 \mathrm{~cm}$ de longitud y $145 \mathrm{~cm}$ de envergadura, de plumaje negro irisado, cabeza y cuello desprovistos de plumas, de color gris pizarra, cola corta y redondeada y patas grises. Vive desde el este y sur de los Estados Unidos hasta el centro de Chile y la Argentina" (DRAE). 
que en el seno de su madre

se comió a su padre vivo?

Inmediatamente respondió Mauriño: «El ratón» y, apurándole para que aplicase a este animal lo que se expresa en el enigma, dijo: "Yo no me calentaré la cabeza en andar combinando propiedades. Lo cierto es que en eso de comer a su padre vivo, el ratón es capaz de comer a su padre, a su madre y a toda su generación, pues no he conocido semejante heliogábalo" ${ }^{59}$. En otra ocasión se trataba de que desatase el siguiente:

\section{¿Cuál es el animal}

hijo adoptivo del viento,

que dejando su elemento

vive en la duda inmortal?

Ciego al bien y lince al mal

obra unos mismos efectos,

mas con distintos conceptos

que aunque en él todos se implican

si son necios lo publican,

lo callan si son discretos.

Propuesto que fue el enigma, respondió Mauriño sin detenerse: «Eh, ya sé lo qué es: el mayate ${ }^{60}$, porque andando este animal tropezando con las paredes puede decirse que es ciego, al bien por que no ve por donde anda, $y$ lince al mal porque sólo advierte en andar dando calabazadas».

Este caballero, pues, hacía a Sancho Panza, pero para que no faltase la gran Dulcinea del Toboso, don Athanasio Aedo hacía este papel vestido del mismo traje que traía aquella labradora, en quien transformaron los encantadores la bella dama de don Quijote, según lo persuadió al amo el bellaco del escudero. En la mano tráa un pendón con los versos que a su tiempo se dirán. Sentado pues a la mujeriega

59 "Persona dominada por la gula» (DRAE).

${ }^{60}$ «Del nahua mayatl. $1 . \mathrm{m}$. Hond. y Méx. Escarabajo de distintos colores y de vuelo regular. 2 . m. coloq. Méx. Hombre homosexual» (DRAE). E1 doble sentido permite crear una polisemia de sentido a propósito de la sexualidad de Mauriño. en una haca ${ }^{61}$ o bestia de albarda ${ }^{62}$, acompañaba a don José María Bocarando, que venía al pie del caballo de don Rodríguez imitando a la dueña Dolorida, con sus tocas muy reverendas y con los ojos llorosos, a guisa de suplicante, para que se le deshiciera el entuerto, que le traía de tan mal talante, a cuya demanda con el rostro mesurado, contestaba así el mismo don Rodríguez:

- La tengo dicho a vuestra merced que el cielo me echó a luz para socorro de los menesterosos y con ayuda de Dios, y de aquella dulce enemiga mía, --decía esto volviendo el rostro a don Athanasio Aedo--, que aunque los encantadores y malandrines que me persiguen hayan trocado su color volviéndolo moreno y disfrazado su hermosura bajo el tosco velo de una soez aldeana, jamás podrán contrastar el valor de este esforzado brazo, que ha de ser todo el remedo de su cuita, dando felice cima a ese desafuero y desaguisado que la aflige.

Y más cuando la señora doña Dolorida, o como se llamase -añadió Mauriño-, es merecedora por su buen término, de que mi señor don Quijote o don Rodríguez, que todo es uno, eche el resto a su inacabable valentía en su defensa, porque he oído [...] que donde las dan las toman, y que no hace la [...] en un año, cuanto paga en una hora; pero a mí tanto se me da de lo que va como de lo que viene, y eso [deparan] los azotes al verdugo, no me acomoda, pues ojos que no ven corazón que no siente.

- Calla - le dijo enfadado don Rodríguez-, que ignoro a qué vienen tantos refranes como has ensartado en un momento, más a propósito eres para una noche buena que para escudero de un caballero andante.

-Entiendo bien la sátira - replicó Mauriño-, y conozco que me ha dicho vuesa merced, en términos disfrazados, que para hacer el papel de Bato $^{63}$ en algún coloquio pastoril de navidad tengo bastante suficiencia. Es cierto que soy sencillo por naturaleza, pero con algunos ribetes de malicioso. Pero ojo al tres, que si yo soy a propósito para pastor, otros son para nada.

${ }^{61}$ Ya en desuso, es lo mismo que jaca.

62 Una bestia de albarda es un asno y uera usado como fórmula en las sentencias de causas criminales cuando se condenaba al reo a un castigo afrentoso» (DRAE).

${ }_{6.3}$ Bato, personaje de la mitología griega asociado a la tartamudez. 
Las siguientes boleras ${ }^{64}$ que cantará la música, explicarán lo que dice el mal andante caballero:

\author{
Otro papel no he hallado \\ que le acomode, \\ mi señor don Rodríguez \\ que el de Quijote; \\ de mal talante \\ parece que le he visto, \\ pero adelante. \\ Es su rocín muy flaco, \\ largo de cuerpo, \\ amarillo su rostro, \\ muy quijotesco. \\ $\mathrm{Y}$ aunque es muy cierto \\ que esto pasa por dicho, \\ es dicho de hecho. \\ Luego que te vi, dije, \\ del caballero \\ de la triste figura \\ eres remedos, \\ y es caso llano \\ que desfacer entuertos \\ es vertú [ca...] \\ Las aventuras quiere \\ el que las busca, \\ pero salir bien de ellas \\ es por ventura. \\ Tendrás presente \\ cuanto muelen los palos \\ de los yanqueses. \\ Después de una contienda, \\ ya te lo aviso, \\ saldrás escarmentado \\ y a saz ferido, \\ pero no te hace
}

${ }^{64}$ "Aire musical popular español, cantable y bailable en compás ternario y de movimiento majestuoso y Canción de ritmo lento, bailable, originaria de Cuba, muy popular en el Caribe, de compás de dos por cuatro y letras melancólicas» (DRAE).
si eres la flor y espuma
de los andantes.
Encontrarás castillos,
y no lo dudes
en que te burlen tanto
como el del duque.
Altisidora,
la Trifaldi y la Dueña
te han de hacer mofa

Tenlo presente, que después dije a don José Manuel Mauriño:

Tienes mucha semejanza,

no sólo en las producciones,

sino aun en muchas acciones

con el grande Sancho Panza.

Esto sólo es una chanza,

pero, desde luego,

que pues no bastó mi ruego

y que estudiar no quisiste,

si con los bobos dormiste,

entre bobos anda el juego.

Que se ahoga a tu parecer

el vejamen no lo digas,

porque sin tu ajo las migas

muy bien se sabrán hacer.

Contribuir no es menester

ni que asistas se requiere

$\mathrm{y}$, si alguno presumiere

que no sé hablar cara a cara,

como si aquí te mirara,

he de hablar de donde diere.

Continuamente mostrabas

lo sencillo en discurrir;

por Bato habías de salir

con la batea de las babas.

Siempre de Belén tratabas

no te sonaba mal

del Dios nacido el portal,

que teniendo oficio en él

te llevaba a hacer papel 
la inclinación natural.

Cuando así adivinar quieres

Bato te calificas,

pues que nunca especificas

tus cándidos pareceres;

dispara como quisieres

y porfia sin fundamento,

que yo decir sólo intento

que a muchos inficionaste

y lo bobo les pegaste,

que un bobo sólo hace ciento.

Así hablaba a este caballero, cuando reflexionando en la figura rara de don Athanasio Aedo del Toboso, digo de doña Dulcinea del Toboso, no puede contener mi musa, que desde luego se desató en los versos siguientes:

Eres la gran Dulciné-,

querida del gran Quijo-,

por quien los encantado-

disfrazaron tu belle-

Esto es lo que trae inquie-

$y$ hace la vida insufri-

de tu dueño don Rodri-.

;Oh Quijote, que es todo u-,

pues de tu ausencia la pu-

lo tiene [avas] mal feri-

$Y$ pues es tiempo que se sepa el contenido de aquellos versos que venían escritos en el pendón, silencio y al caso:

En este traje mudada,

que es muy proprio de la aldea, se queja desfigurada

y en labradora trocada

la agraciada Dulcinea

del Toboso.
2

Es la envidia malicios

la que la ha puesto tan fea

aunque era princesa hermosa

es la suerte lastimosa

de la sin par Dulcinea

del Toboso
Es muy rara su mudanza porque su caída se vea;

y el bellaco Sancho Panza dice que no es semejanza de la que era Dulcinea del Toboso.

La que excedía en hermosura

a la bella Casildea,

ahora no es ni su figura.

Ó́dos, que tales orejas respondió Mauriño: "Que no me daré yo un azote, aunque se quedasen encantadas todas las Dulcineas del mundo. ¿Qué tienen que ver mis carnes con su encantamiento? Y más cutando yo no he parido a esa señora imaginaria del Toboso, que se le ha venido a las mientes a mi señor don Rodríguez, que tal sea mi salud; como yo creo que es una locura antojadiza, pero suponiendo que yo no me he de dar ni un azote ni medio, por que esto es pedir peras al olmo, sería bueno que a esta doña Dolorida...». «Dueña, querrás decir, que no doña, Sancho - le interrumpió don Rodríguez». «Doña o dueña -replicó Mauriño-. Todo sale allá, decía, pues que sería muy razonable dar a esta señora que viene aquí no más gimiqueando un pasa lomo para que enjugase sus lágrimas, que cierto que tengo el corazón muy doloroso de verla tan [plavu]rienta». "Eso haré de buena gana -le respondí-, aunque digan que..."

Musica in luctu, intempestiva narratio

La dueña Dolorida

que representas

es para con tu llanto

niña [veteta].

Tan llorona eres,

que una vieja a tu lado

moza parece.

Si de todo te apuras

y compadeces,

A Sancho le ha de costar, de azotes más de un milla l poder desencantar a la hermosa Dulcinea del Toboso.

de la sin par Dulcinea el Toboso.

Tanta así es la desventura 
padeces tantos males cuantos adviertes.

No son bastantes

a dar agua a tus ojos

todos los mares.

Ese desaguisado

que te atormenta

tormenta ha levantado

de muchas penas.

No poca parte

le cabe a don Rodríguez

de tus pesares.

4

Si llora[s] de tu cuita

en el empeño,

empeño es, y no hay duda,

pero muy tierno.

Ten por sabido

que el sueño a aquel que llora

siempre se le ha ido.

Menos que tú por su asno

Sancho suspira,

[pira] es de compasión

la dolorida,

$y$ no de fuego,

que tanta agua apagara

cualquiera incendio.

Déjate pues de ruegos,

no estés hablando.

Blando es, y mucho, el pecho

de nuestro hidalgo.

$\mathrm{Y}$ en el consuelo

que [inauditas] hazañas

hará su esfuerzo.
Bibliografía CITADA

ANDERson, Benedict, Comunidades imaginadas. Reflexiones sobre el origen $y$ la difusión del nacionalismo [1983], trad. E.L. Suárez, México D.F., FCE, 1993.

Bordreu, Pierre, "Espacio social y poder simbólico", en Cosas dichas, Barcelona, Gedisa, 1987, pp. 127-142.

Buezo, Catalina, La mojiganga dramática. De la fiesta al teatro, Kassel, Reichenberger, 1993.

Carilla, Emilio, Cervantes y América, Buenos Aires, Universidad, 1951.

CARreño, Alberto María, Efemérides de la Real y Pontificia Universidad de México según sus libros de claustros, México, UNAM, 1963, vol. 1.

Coello UGalde, Francisco José, "Relación de juegos de cañas, que fueron cosas muy de ver. Aquí se consignan los más curiosos e importantes habidos desde 1517 hasta 1815 en Nueva España», Boletín del Instituto de Investigaciones Bibliográficas, 1, 1987, pp. 252-307.

EgIDO, Aurora, "Certámenes poéticos y arte efimero en la Universidad de Zaragoza (siglos XVI y XVII)», en Cinco estudios humanísticos para lo Universidad de Zaragoza en su centenario IV, Zaragoza, Caja de Ahorros de la Inmaculada, 1983, pp. 9-78.

- "De ludo vitando. Gallos áulicos en la Universidad de Salamanca», El Crotalón. Anuario de Filología Española, 1, 1984, pp. 609-648.

Eguiguren, Luis Antonio, El paseo triunfal y el vejamen del graduado, Lima, T. Scheuch, 1949.

GIVANEL MAS, Juan, «Una mascarada quixotesca celebrada a Barcelona», Butllet" de l'Ateneu Barcelonès, Barcelona, L'Avenç, 3, 1915, pp. 127-151.

GonzAlBo Arzpuru, Pilar, "Las fiestas novohispanas: espectáculo y ejemplo», Mexican Studies, 9, 1, 1993, pp. 19-45.

GonzÁlez Obregón, Luis, México viejo, Madrid, Alianza, 1999.

HuIzINGA, Johan, Homo ludens, Madrid, Alianza, 1999.

ICAZA, Francisco A. de, El Quijote durante tres siglos, Madrid, Imprenta de Fontanet, 1918.

IFFLAND, James, De fiestas y aguafiestas: risa, locura e ideologia en Cervantes $\gamma$ Avellaneda, Madrid, Universidad de Navarra-Iberoamericana-Vervuert, 1999.

LASSO DE LA VEGA, Miguel, "Apuntes sobre la Lima del siglo xviI", Mercurio peruano, $24,184,1942$, p. 362 .

León Pinflo, Diego, Semblanzas de la Universidad de San Marcos, traducción del latín de Luis Antonio Eguiguren, Lima, T. Scheuch, 1949, pp. 71-77.

LeONARD, Irving A., Los libros del conquistador, México D.F., FCE, 1953.

- La época barroca en el México colonial, México D.F., FCE, 1976. 
Lobato, María Luisa, "El Quijote en las mascaradas populares del siglo XVII", en Cervantes. Estudios en la vispera de su centenario, Kassel, Reichenberger, 1994, vol. II, pp. 577-604

López Estrada, Francisco, «Fiestas y literatura en los Siglos de Oro: la Edad Media como asunto festivon, Bulletin Hispanique, 84, 1982, pp. 291-327.

MADRAzo, Jorge, El sistema disciplinario de la Universidad Nacional de México, México D.F., UNAM, 1980.

Madroñal, Abrahan, «Sobre el vejamen de grado en el Siglo de Oro. La Universidad de Toledo", Epos, X, 1994, pp. 203-231.

Méndez Arceo, Sergio, La Real y Pontificia Universidad de México. Antecedentes, tramitación y despacho de las Reales Cédulas de erección, México D.F., UNAM, 1952.

Mendoza, Vicente T., Vida y costumbres de la Universidad de México, México D.F., Instituto de Investigaciones Históricas, 1951.

Pinheiro da VeiGa, Tomé, Fastiginia o Fastos Geniales, trad. y notas de N. Alonso Cortés, Valladolid, Servicio de Publicaciones del Excmo. Ayuntamiento, 1973

Redondo, Agustin, "En busca del Quijote. El problema de los afectos», en Cuatrocientos años del ingenioso hidalgo. Colección de Quijotes de la Biblioteca Cervantina, Siglos XVII y XVIII y Cuatro estudios sobre El Quijote, eds. B. López de Mariscal y J. Farré, México D.F., FCE -ITESM, 2004, pp. 51-65.

Robles, Antonio de, Diario de sucesos notables (1665-1703), México D.F., Porrúa, 1946, vol. 3.

Rodríguez Cruz, Águeda María, La universidad en la América hispánica, Madrid, Editorial Mapfre, 1992.

ROORIGUEZ DE LA FLOR, Fernando, Barroco. Representación e ideología en el mundo hispánico (1580-1680), Madrid, Cátedra, 2002.

Rodríguez Marín, Francisco, El Quijote $y$ don Quijote en América, Madrid, Librería de los sucesores de Hernando, 1911.

Rojas Garcidueñas, José, Presencias de don Quijote en las artes de México, Monterrey, Tecnológico de Monterrey, 1965.

Romero de Terreros, Manuel, Torneos, mascaradas y fiestas reales en la Nueva España, México D.F., Cultura, 1918

RUtida, Pedro J., «La vigilancia inquisitorial del libro con destino a América en el siglo XVIr», en Grafias del imaginario. Representaciones culturales en España y América (siglos XVI-XVIII), comp. C. Alberto González y E. Vila, México D.F, FCE, 2003, pp. 140-154.

SuARDo, Juan Antonio, Diario de Lima 1629-1639, ed. Rubén Vargas Ugarte, Lima, Universidad Católica del Perú-Instituto de investigaciones históricas, 1936.

SuÁrez de Peralta, Juan, Noticias históricas de la Nueva España, Madrid, Imprenta de Manuel G. Hernández, 1878.
SubIrats, Eduardo, "Theatrum Mundi», Astrágalo. Cultura de la arquitectura y la ciudad, 11, 1999, pp. 9-24.

ZURIÁN, Carla Isadora, Fiesta barroca mexicana y celebraciones públicas en el siglo xvm: la Inmaculada Concepción de Nuestra Señora, tesis de licenciatura, México, UNAM, 1995, depositada en el Archivo de la Biblioteca Nacional de Antropología e Historia con la signatura TSUN Z5055 UNH 565. 


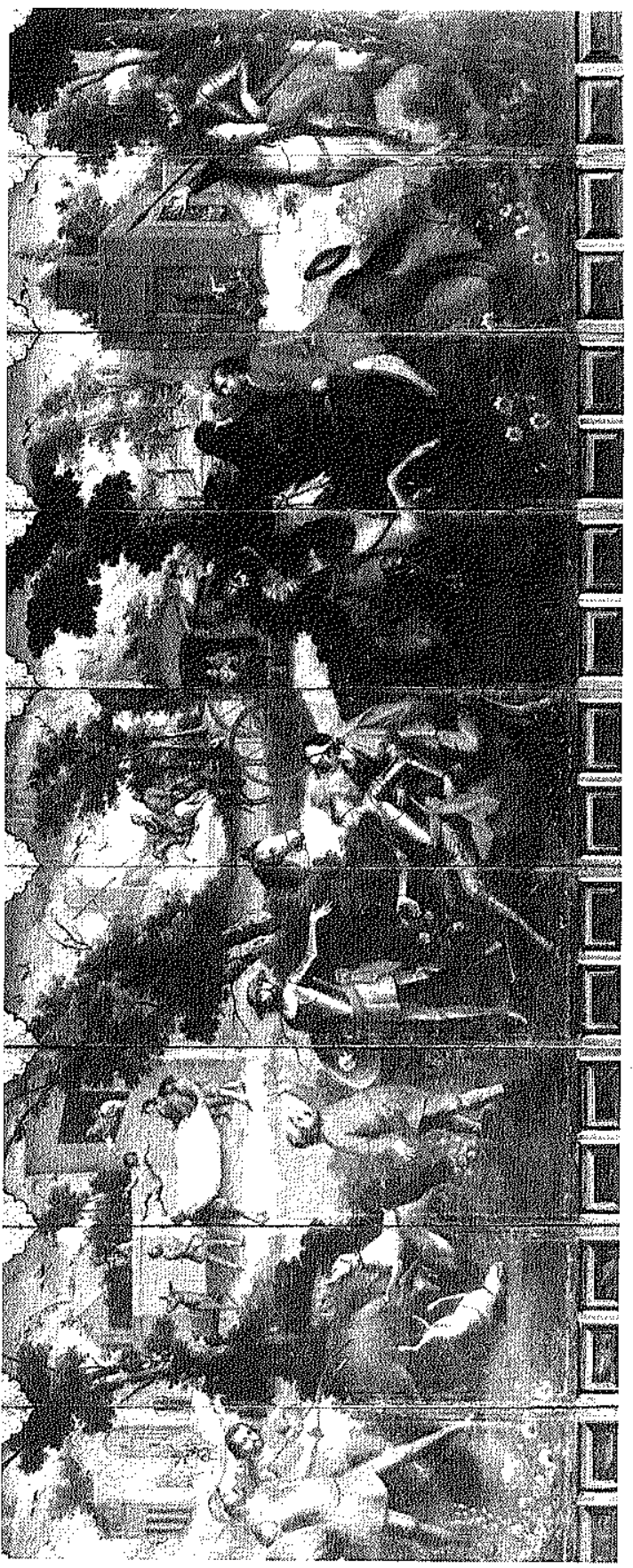

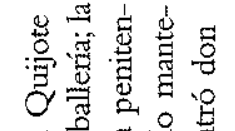

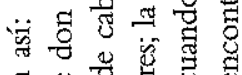

$$
\begin{aligned}
& \text { 5 . }
\end{aligned}
$$

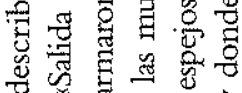

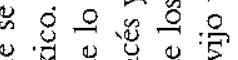

$$
\begin{aligned}
& \text { w }
\end{aligned}
$$

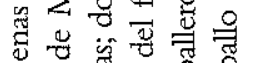

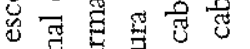

$$
\begin{aligned}
& \text { क 당 च च }
\end{aligned}
$$

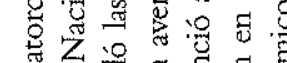

$$
\begin{aligned}
& \text { o } 8 \text { is }
\end{aligned}
$$

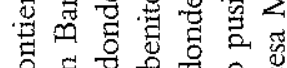

$$
\begin{aligned}
& 0: 0
\end{aligned}
$$

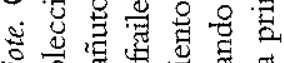

$$
\begin{aligned}
& \text { वे 五 }
\end{aligned}
$$

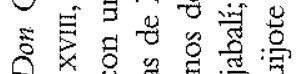

$$
\begin{aligned}
& \text { 응 }
\end{aligned}
$$

